\title{
A APOSENTADORIA ESPECIAL
}

Luciana Ferreira de Souza, Adriana Aparecida Giosa Ligero

Universidade do Oeste Paulista - UNOESTE. Curso de Direito, Presidente Prudente - SP. E-mail: souzalu79@hotmail.com

\section{RESUMO}

O presente trabalho busca analisar o benefício previdenciário denominado aposentadoria especial. Sendo que, a Lei Complementar 8.213/91, trata da aposentadoria especial nos artigos 57 e 58, como também acaba por analisar sua evolução legislativa, os requisitos exigidos aos segurados que exercem atividade em ambiente de trabalho expostos a agentes nocivos prejudiciais à saúde e à integridade física. A concessão da aposentadoria especial é repleta de controvérsias por parte do INSS (Instituto Nacional do Seguro Social), que na maioria das vezes se dá em razão das constantes alterações legislativa. Sendo assim, este estudo objetiva debater os aspectos legais, as dificuldades encontradas por contribuintes no que diz respeito à concessão do beneficio e o entendimento dos Tribunais diante da negativa da Previdência Social, bem como a exigência de laudo técnico, o preenchimento do formulário do P.P.P. (Perfil Profissiográfico Previdenciário), pelas empresas. Trata-se, de um dos benefícios previdenciários mais complexos.

Palavras-chave: Aposentadoria Especial. INSS (Instituto Nacional do Seguro Social). Alteração Legislativa.

\section{A SPECIAL RETIREMENT}

\begin{abstract}
This paper analyzes the special retirement pension benefit called. Since, Complementary Law $8213 / 91$, this special retirement in Articles 57 and 58, and also turns out to analyze its legislative developments, the requirements to policyholders who exercise activity in the workplace exposed to harmful agents harmful to health and physical integrity. The granting of special retirement is fraught with controversy by the INSS (National Social Security Institute), which most often occurs because of constant legislative changes. Therefore, this study aims to discuss the legal aspects, the difficulties encountered by taxpayers with respect to the grant of the benefit and understanding of the Courts on the denial of Social Security, as well as the requirement of a technical report, fill the form of PPP (Profile Social Security Professional), by companies. It is, one of the most complex pension benefits.
\end{abstract}

Keywords: Special Retirement. INSS (National Social Security Institute). Legislative change 
INTRODUÇÃO E OBJETIVO

O objetivo principal desse trabalho é a reflexão sobre a dificuldade em entender a aplicação dos preceitos que regem a aposentadoria especial, consistente nos aspectos práticos e controvertidos para a concessão da aposentadoria especial.

Os resultados apontam que as maiores dificuldades encontradas pelos segurados para concessão da aposentadoria ora em comento, é a dificuldade de atender as exigências impostas pelo INSS (Instituto Nacional do Seguro Social), com relação a apresentação da cópia do laudo técnico que comprove as condições ambientais de trabalho e o tempo despendido para a conclusão de todo o processo administrativo. Outros requisitos também são exigidos pela Previdência Social, tais como: a) a condição de segurado com ao menos 180 (cento e oitenta) contribuições mensais, cf. art. 57 caput e art. 25, ambos da Lei 8.213/91; b) a comprovação de exposição a agentes nocivos prejudiciais à saúde e à integridade física por meio de um formulário denominado PPP (Perfil Profissiográfico Previdenciário), sendo esse preenchido pelas entidades onde laborou o segurado com base no laudo técnico de condições ambientais do trabalho expedido por médico do trabalho ou engenheiro de segurança do trabalho cf. art. 58, §10, da Lei $8.213 / 91$; c) uso de equipamentos de proteção individual ou coletivo, cf. art. 58 , § 2으, da Lei $8.213 / 91$.

Mesmo cumprindo todas as exigências estabelecidas em lei, o segurado encontra dificuldades para receber esse benefício. Sua concessão mediante a solicitação junto a Previdência Social se torna incerta, pois alguns períodos de contribuição não são reconhecidos como especiais, fazendo muitas vezes com que o segurado tenha que buscar seu direito se utilizando do meio judicial.

A aposentadoria especial é regulamentada na Lei 8.213/91, mais precisamente nos artigos 57 e 58, o referido beneficio será concedido aos quinze, vinte ou vinte e cinco anos de contribuição a Previdência Social. Entretanto o próprio ordenamento prevê requisitos para a sua concessão, sendo a finalidade deste beneficio amparar o trabalhador que laborou em condições nocivas a saúde e a integridade física, sendo que essa exposição aos agentes nocivos deverá ocorrer de forma habitual e permanente, não ocasional nem intermitente.

Nas linhas que se seguem se analisará jurisprudência e doutrina sobre o tema em razão da complexidade do instituto e da dificuldade de compreensão e interpretação para o reconhecimento e concessão da aposentadoria especial.

\section{MÉTODOS}


A pesquisa bibliográfica foi o principal meio de obtenção de informações neste trabalho ao lado da jurisprudência e das considerações históricas. Num estudo, partindo-se do raciocínio hipotético dedutivo, foram construídas as bases do trabalho, numa interpretação reflexiva e dialética.

\section{DESCRIÇÃO DO CASO}

A aposentadoria especial é um beneficio de caráter preventivo, alguns doutrinadores entendem ser um instrumento de técnica protetiva do trabalhador, já que visa a sua proteção, com objetivo de buscar a compensação dos desgastes resultantes da exposição do trabalhador, aos agentes nocivos prejudiciais, afastando-o antecipadamente do ambiente prejudicial à sua saúde ou integridade física, prevenindo doenças provenientes do referido local de trabalho (RIBEIRO, 2013, p.31).

Inicialmente a aposentadoria especial foi instituida pela Lei $3.807 / 60$ no artigo 31 , Lei Orgânica da Previdência Social (LOPS), referida lei exigia limite minimo de idade, ou seja, o segurado teria que contar com no minimo cinquenta anos de idade e ter trabalhado quinze, vinte ou vinte e cinco anos em atividades consideradas insalubres, penosas ou perigosas (MELLO, 2013, p.235/243).

Com advento da Lei 5.440/68, o artigo 31 da Lei 3.807/60 foi alterado, não mais se exigindo a idade minima de cinquenta anos para a concessão do beneficio, mas, em contrapartida estabeleceu previlegios à determindas categorias que não estavam expostas a risco, como por exemplo, no caso de um engenheiro, que não elaborava o trabalho no interior de uma mina e acabava por se aposentar com poucos anos de serviço, por simplismente pertencer à categoria de engenheiros, ou seja, não exigia que se provasse a exposição permanente a agentes nocivos, pois as atividades especiais eram previstas pelos Decretos 53.861/64 e 83.080/79 (MELLO, 2013, p.235/243).

Em 1988, veio uma nova Constituição que, estabeleceu em seu no artigo 201, § 1으, a possibilidade de criação de normas que regulamentassem as atividades exercidas em condições especias que prejudicasse a saude ${ }^{1}$, vedando a criação de critérios diferenciados para os beneficiários do regime geral de previdência (MELLO, 2013, p.235/243).

Com relação à aposentadoria especial, tratou a Lei no 8.213/91, em seu artigo 57, ao passo que no artigo 58, foi estabelecido que as atividades profissionais prejudiciais à saúde ou à integridade física, seriam previstas em lei específica. Esse instituto não trouxe grandes

\footnotetext{
${ }^{1}$ Art. $201 \S 1$ - [...] ressalvados os casos de atividades exercidas sob condições especiais que prejudiquem a saúde ou a integridade física [...]. 
modificações, permanecendo por exempolo a concessão do beneficio em razão da categoria e não pelo fato do segurado estar exposto a agentes nocivos.

Nesse sentido Ribeiro (2013, p. 99).

Conforme se depreende da redação da Lei 8.213/91, o enquaqramento como tempo como especial passou a depender do fato do trabalhador pertencer a esta ou aquela atividade profissional.

Percebe-se que inicialmente a aposentadoria especial era concedida de acordo com a atividade profissional estabelecida pelo regulamento à época, e não pelo ambiente de trabalho. Portanto a lei continuou por considerar o tempo de serviço especial aquele exercicido por determindada categoria, e não por trabalhar em ambiente insalubre.

De acordo com Ibrahim (2013, p. 622) a aposentadoria especial visa:

[...] a atender segurados que são expostos a agentes físicos químicos e biológicos, ou uma combinação destes, acima dos limitaes de tolerância aceitos, o que se presume produzir a perda da integridade física e mental em ritimo acelerado.

Assim, trata-se de um benefício social devido em razão da comprovação do exercício de trabalho pelo segurado de atividade considerada gravosa à sua saúde física ou mental. Quanto mais desgastante for o labor executado pelo segurado, menor será o tempo de serviço necessário para o mesmo se aposentar.

Infere-se assim que, mesmo após a edição da Lei 8.213/91, as atividades consideradas nocivas a saude e a integridade física prevista nos Decreto 53.861/64 e 83.80/79, continuaram a prevalecer.

Ocorre que, a Lei 8.213/91, passou por constantes alterações, causando ao instituto da aposentdoria especial diversas controversas por parte do INSS. Senão Vejamos.

No ano de 1997, foi aprovado o Decreto 2.172, que revogou expressamente aqueles decretos, referido decreto foi editado conforme a Lei 9.032/95, que vedava a concessão da aposentadoria especial por categoria profissional, como por exemplo, a categoria dos eletricistas, como também vedou a conversão do tempo de serviço comum em especial, dentre outras, (HORVATH JÚNIOR, 2005, p. 202).

Desde então parte da confusão esta no enquadramento das atividades especiais, parte dos indeferimentos de pedidos de aposentadoria especial estão relacionados ao tempo em que o segurado laborou suas atividades, ou seja, o segurado que laborou atividades especiais consideradas pelos decretos Decreto 53.861/64 e 83.080/79, ao requerer sua aposentadoria após 
o decreto 2.172, o INSS tem negado o pedido por não ser mais considerada atividade especial. Mas, o tribunal não tem entendido dessa forma.

De acordo com Ribeiro (2013, p. 284), a jurisprudência do Superior Tribumal Justiça tem enetndido:

Previdenciário. Exposição à eletricidade. Atividade especial. O segurado exposto ao agente eletricidade aproveita o respectivo periodo como atividade especial para os efeitos da contagem de tempo de serviço, mesmo após a vigencia do Decreto 2.172/97, cujo rol tem carater exemplificativo. Agravo Regimental não provido. (AgRg no AREsp. 161000/AL - Ari Pargendler - STJ - 1a Turma., un. - Dje 10.09.2013).

Nota-se que mesmo após a edição do Decreto 2.172/97, o segurado tem o direito ao reconhecimento do tempo de labor em condições especias, mesmo não sendo considerado pelo referido decreto, tal entendimento se deu em respeito ao direito adiquirido e o principio da irretroatividade, ambos previstos constituionalmente, ou seja, mesmo sendo por categoria se tem reconhecido. (RIBEIRO, 2013, p. 284).

Ademais com relação a estes segurados, outro ponto divergente se dava quando do pedido de conversão do tempo especial para comum, em razão de não mais perdurar o enquadramento por categoria, mas tem-se entendido que o direito a conversão deve prevalecer de acordo com a legislação da época, pois, o não reconhecimento ofenderia o princípio da isonomia (IBRAHIM, 2012, p. 633).

Em 1996, foi instituída a Medida Provisória 1.523, alterando o $§ 10$ do artigo 58 da Lei 8.213/91, exigindo que as empresas devessem informar por meio do LTCAT (Laudo Ténico de Condição Ambiental de Trabalho), a comprovação de exposição do trabalhador a agentes nocivos existentes na empresa e ainda informar sobre o uso de equipamentos de proteção individual ou coletivo, (EPI/EPC), que eliminasse ou reduzisse a intensidade do agente agressivo com relação ao limite de tolerância, bem como a indicação sobre a adoção pelo respectivo estabelecimento, quando este sujeitar seus colaboradores a trabalhos especiais.

Nesse ponto, surge mais uma polêmica, o referido laudo seria exigido na data da publicação da Lei 9.032/95. Porém, a referida lei não previa futuramente a exigencia desse laudo, a justificativa se deu em razão da lei ter vedado o enquadramento das atividades especiais por categoria. Assim em razão de não existir previsão na lei, surgiu a grande divergencia na questão da data exata para a exigência do laudo (LTCAT). Em 97 a medida porvisória foi convertida na Lei 9.528.

O Superior Tribunal de Justiça passou a decidir da seguinte forma: 
EMENTA: PREVIDENCIÁRIO - RECURSO ESPECIAL - APOSENTADORIA POR TEMPO DE SERVIÇO - CONVERSÃO DE TEMPO ESPECIAL EM COMUM - POSSIBILIDADE LEI 8.213/91 - LEI 9.032/95 - LAUDO PERICIAL INEXIGÍVEL - LEI 9.528/97. - A necessidade de comprovação da atividade insalubre através de laudo pericial, foi exigida após o advento da Lei 9.528, de 10.12.97, que convalidando os atos praticados com base na Medida Provisória no 1.523, de 11.10.96, alterou o § 1으, do art. 58, da Lei 8.213/91, passando a exigir a comprovação da efetiva exposição do segurado aos agentes nocivos, mediante formulário, na forma estabelecida pelo INSS, emitido pela empresa ou seu preposto, com base em laudo técnico das condições ambientais do trabalho, expedido por médico do trabalho ou engenheiro de segurança do trabalho. Tendo a mencionada lei caráter restritivo ao exercício do direito, não pode ser aplicada à situações pretéritas, portanto no caso em exame, como a atividade especial foi exercida anteriormente, não está sujeita à restrição legal. Precedentes desta Corte. Recurso conhecido, mas desprovido.

Assim, permanece na jurisprudência o entendimento de que, somente após o advento da Lei 9.528/97, poderá se exigir do segurado a comprovação da exposição a agentes nocivos por meio do formuário, é importante ressaltarmos que o uso dos equipamentos de proteção individual ou coletivo não exime o empregador de suas responsabilidades, como também existem precedentes no sentido de que o uso dos equipamentos não afasta por si só o direito ao benefício.

Consoante explica Ribeiro (2013, p. 278).

Por outro lado existe entendimento no sentido de que, ainda que os documentos apresentados pelo segurado façam mençao à indicação, fornecimento e exigencia de uso de equipamentos de proteção, individual tal fato não afasta a caracterização das atividades exercidas pelo trabalhador como especiais.

A partir de 2004, veio uma nova alteração legislativa exigindo que a comprovação da efetiva exposição do segurado aos agentes nocivos prejudiciais à sua saúde ou à sua integridade física, passou a ser exigido por meio do formulário PPP (Perfil Profissiográfico Previdenciário), com base em normas estabelecidas pelo INSS, emitido pela empresa onde o segurado laborou baseado no LTCAT (Laudo Técnico de Condições Ambientais do Trabalho) expedido por médico do trabalho ou engenheiro de segurança do trabalho e fornecer ao trabalhador uma cópia autêntica deste documento em caso de rescisão do contrato de trabalho, sendo que, as empresas que não atenderem a obrigatoriedade estarão sujeitas à multa.

Nota-se, que o perfil profissiografico previdenciário é emitido com base no LTCAT (Laudo Técnico de Condições Ambientais do Trabalho), porém se tem entendido que a apresentação do formulário P.P.P. junto ao INSS (Instituto Nacional do Seguro Social), substitui o Laudo Ténico, haja vista que é elaborado com base no laudo. 
Assim entende a jurisprudência atual:

PEDIDO DE UNIFORMIZAÇÃO. PREVIDENCIÁRIO. PARADIGMAS INVOCADOS. APOSENTADORIA POR TEMPO DE CONTRIBUIÇÃO. CONVERSÃO DE TEMPO ESPECIAL EM COMUM. POSSIBILIDADE. EXPOSIÇÃO A RUÍDOS ACIMA DOS LIMITES DE TOLERÂNCIA. CONSTATAÇÃO. TEMPUS REGIT ACTUM. FORMULÁRIO EXIGIDO. PPP. APRESENTAÇÃO DE LAUDO TÉCNICO PELO SEGURADO NA VIA ADMINISTRATIVA. DESNECESSIDADE, IN CASU. ART. 161, INC. IV, § 10, DA INSTRUÇÃO NORMATIVA INSS/PRES № 27, DE 30/04/2008. PRECEDENTE DESTA TNU JEF's. INCIDENTE CONHECIDO E PROVIDO. I. Aduzindo os acórdãos paradigmas no sentido de que o perfilprofissiográfico previdenciário - PPP emitido pela empresa onde o segurado desempenhou atividades especiais deve ser reconhecido para fins de comprovação da atividade, com a consequente conversão do tempo, segundo o índice previsto em lei ou regulamento e, havendo o acórdão da Turma Recursal de origem dado provimento apenas parcial ao recurso inominado em função do entendimento daquele colegiado segundo o qual apenas após 01/01/2004 passou possível o reconhecimento da especialidade somente por meio do PPP,sem a necessidade de apresentação do laudo técnico pelo segurado, é derigor o reconhecimento de similitude fática [...]

Como visto o referido formulário substitui o laudo técnico, sendo um documento suficiente para comprovação das atividades nocivas.

Outra grande divergencia se deu pelo fato da Medida Provisória 1.663/98, pretender extinguir o direito à conversão de tempo especial em comum, à referida medida provisória foi convertida na Lei $9.711 / 98$, que previa a possibilidade de conversão do tempo especial em comum, somente se o segurado tivesse laborado um percentual para a aposentação especial, mas não logrou exito (IBRAHIM, 2012, p. 634).

Mas isso não foi tudo, persistiram as constantes alterações legislativas, em 1999, veio o decreto o Decreto 3.048/99, vedando totalmente o direito à conversão do tempo especial em comum, a partir de então todos os pedidos passaram a ser negados.

Entretanto, 2003 veio o Decreto 4.827, permitindo a conversão do tempo especial em comum, como também determinou que à conversão se aplicasse ao trabalho prestado em qualquer período, sendo assim a discussão foi superada (RIBEIRO, 2013, p. 14-15).

Assim dispõe a jurisprudência:

PROCESSUAL CIVIL. PREVIDENCIÁRIO. ATIVIDADE INSALUBRE. CONVERSÃO. PERÍODO ANTERIOR À VIGÊNCIA DA LEI 6.887/81. POSSIBILIDADE. ARTIGO 70 DO DEC. 3.048/99 COM REDAÇÃO DADA PELO DEC. № 4.827/03. AGRAVO. ARTIGO 557 § 1 DO CPC. DECISÃO BASEADA EM JURISPRUDÊNCIA DESTE TRIBUNAL- 1.0 artigo 70 do Decreto no 3.048/99, com redação dada pelo Decreto no 4.827/2003, permitiu a conversão do tempo especial em comum ao serviço laborado em qualquer período. 2. Agravo do INSS improvido. 
Nota-se que mesmo com a edição do Decreto 4.827/03, o Instituto Nacional do Seguro Social, ainda nega o pedido de conversão do tempo de serviço especial em comum, restando ao segurado buscar o direito ao benefício somente por via judicial.

\section{CONCLUSÃO}

Conclui-se que os trabalhadores expostos a agentes nocivos prejudiciais à saúde e à integridade física apresentam dificuldade para ver seu direito reconhecido na seara administrativa. Assim, quando se trata da aposentadoria especial, esta, ao ser solicitada, se torna incerta, pois, a Previdência Social apresenta entendimentos adversos com relação aos documentos apresentados no ato da solicitação, em decorrência das constantes alterações legislativas.

Acrescenta-se ainda, que mesmo quando o segurado apresenta o P.P.P. (Perfil Profissiográfico Previdenciário), elaborado com base no LTCAT (Laudo Técnico de Condições Ambientais do Trabalho), a forma de elaboração do referido documento, pode gerar diversas formas de interpretação, trazendo por consequência, o indeferimento do requerimento em sede administrativa. Obrigando o segurando a buscar a via judicial na tentativa de ver seu pleito reconhecido.

\section{REFERÊNCIAS}

HORVATH JÚNIOR, Miguel. Direito Previdenciário. 5ạ ed. São Paulo: Quartier Latin, 2005.

IBRAHIM, Fabio Zambitte. Curso de Direito Previdenciário. 17ạ ed. Rio de Janeiro: Impetus, 2012.

MELLO, Sergio Renato de. Comentário e Interpretação no Regime Geral da Previdência Social. 1ạ ed. São Paulo: LTr, 2013.

RIBEIRO, Maria Helena Carreira Alvim. Aposentadoria Especial. Regime Geral da Previdencia Social. 6a ed. Curitiba: Jurua, 2013.

SANTA CATARINA. Superior Tribunal de Justiça. Ementa. Recurso Especial no 436.414/02. Recorrente: Instituto Nacional do Seguro Social. Recorrido: Augusto Jagelski. Relator: Ministro Jorge Scartezzini. 28 de abril de $2004 . \quad$ Disponível em: $<$ http://www.stj.jus.br/SCON/jurisprudencia/toc.jsp?tipo visualizacao=null\&processo $=436414$ $\& b=A C O R \&$ thesaurus=JURIDICO $>$. Acesso em: 10 ago. 2014.

SANTA CATARINA. Turma Nacional de Uniformização. Ementa. Processo no Pedilef 200772590036891. Requerente: Valdemiro Arbeit. Requerido: Instituto Nacional do Seguro Social. Relator: Juiz Federal Ronivon de Aragão. 17 de marco de 2011. Disponível em:< http://tnu.jusbrasil.com.br/jurisprudencia/19100998/pedido-de-uniformizacao-de-interpretacaode-lei-federal-pedilef-200772590036891-sc>. Acesso em: 10 ago. 2014. 
SÃO PAULO. Tribunal Regional Federal da 3a Região. Processo no Apelreex 000052397.2003.4.03.6107. Relator: Juiz Convocado Douglas Gonzales. 07 de outubro de 2013. Disponível em:< $\quad$ http://trf-3.jusbrasil.com.br/jurisprudencia/24601072/apelacao-reexame-necessarioapelreex-523-sp-0000523-9720034036107-trf3 >. Acesso em: 10 ago. 2014. 